\title{
Non-contiguous finished genome sequence of Bacteroides coprosuis type strain (PC139 ${ }^{\mathrm{T}}$ )
}

\author{
Miriam Land ${ }^{1,2}$ Brittany Held ${ }^{1,3}$, Sabine Gronow ${ }^{4}$, Birte Abt ${ }^{4}$, Susan Lucas ${ }^{1}$, Tijana Glavina \\ Del Rio ${ }^{1}$, Matt Nolan ${ }^{1}$, Hope Tice ${ }^{1}$, Jan-Fang Cheng ${ }^{1}$, Sam Pitluck ${ }^{1}$, Konstantinos Liolios ${ }^{1}$, \\ Ioanna Pagani ${ }^{1}$, Natalia Ivanova ${ }^{1}$, Konstantinos Mavromatis ${ }^{1}$, Natalia Mikhailova ${ }^{1}$, Amrita \\ Pati $^{1}$, Roxane Tapia ${ }^{1,3}$, Cliff Han ${ }^{1,3}$, Lynne Goodwin ${ }^{1,3}$, Amy Chen ${ }^{1,5}$, Krishna Palaniappan ${ }^{1,5}$, \\ Loren Hauser $^{1,2}$, Evelyne-Marie Brambilla ${ }^{4}$, Manfred Rohde ${ }^{6}$, Markus Göker ${ }^{4}$, John C. \\ Detter $^{1,3}$, Tanja Woyke ${ }^{1}$, James Bristow ${ }^{1}$, Jonathan A. Eisen ${ }^{1,7}$, Victor Markowitz ${ }^{1,5}$, Philip \\ Hugenholtz ${ }^{1,8}$, Nikos C. Kyrpides ${ }^{1}$, Hans-Peter Klenk ${ }^{4}$, and Alla Lapidus ${ }^{1 *}$ \\ ${ }^{1}$ DOE Joint Genome Institute, Walnut Creek, California, USA \\ ${ }^{2}$ Oak Ridge National Laboratory, Oak Ridge, Tennessee, USA \\ ${ }^{3}$ Los Alamos National Laboratory, Bioscience Division, Los Alamos, New Mexico, USA \\ ${ }^{4}$ DSMZ - German Collection of Microorganisms and Cell Cultures $\mathrm{GmbH}$, Braunschweig, \\ Germany \\ ${ }^{5}$ Biological Data Management and Technology Center, Lawrence Berkeley National \\ Laboratory, Berkeley, California, USA \\ ${ }^{6} \mathrm{HZI}$ - Helmholtz Centre for Infection Research, Braunschweig, Germany \\ ${ }^{7}$ University of California Davis Genome Center, Davis, California, USA \\ ${ }^{8}$ Australian Centre for Ecogenomics, School of Chemistry and Molecular Biosciences, The \\ University of Queensland, Brisbane, Australia \\ ${ }^{*}$ Corresponding author: Alla Lapidus
}

Keywords: strictly anaerobic, non-motile, Gram-negative, mesophilic, chemoorganotrophic, Bacteroidaceae, GEBA

Bacteroides coprosuis Whitehead et al. 2005 belongs to the genus Bacteroides, which is a
member of the family Bacteroidaceae. Members of the genus Bacteroides in general are
known as beneficial protectors of animal guts against pathogenic microorganisms, and as
contributors to the degradation of complex molecules such as polysaccharides. B. coprosuis
itself was isolated from a manure storage pit of a swine facility, but has not yet been found in
an animal host. The species is of interest solely because of its isolated phylogenetic location.
The genome of $B$. coprosuis is already the $5^{\text {th }}$ sequenced type strain genome from the genus
Bacteroides. The 2,991,798 bp long genome with its 2,461 protein-coding and 78 RNA genes
and is a part of the Genomic Encyclopedia of Bacteria and Archaea project.

\section{Introduction}

Strain PC139' (= DSM $18011=$ NRRL B-41113 = JCM 13475) is the type strain of Bacteroides coprosuis which belongs to the large genus Bacteroides, which currently contains 39 members [1,2]. The species epithet is derived from the Greek noun 'kopros' meaning 'feces' and the genitive of the Latin noun 'suis' meaning 'of a pig'. B. coprosuis strain $\mathrm{PC} 139^{\mathrm{T}}$ was isolated from a manure storage pit of a swine facility. One other strain belonging to the same species has been isolated from the same source [2]. Many Bacteroides species are common inhabitants of the intestine where they help to degrade complex molecules such as polysaccharides or transform steroids $[3,4]$. They also play a role as beneficial protectors of the gut against pathogenic microorganisms [5]. However, so far B. coprosuis has not been isolated from an animal itself, therefore the exact habitat and the role the bacterium plays remains unknown. Here we present a summary classification and a set of features for B. coprosuis $\mathrm{PC} 139^{\mathrm{T}}$, together with the description of the complete genomic sequencing and annotation. 


\section{Classification and features}

A representative genomic $16 \mathrm{~S}$ rRNA sequence of strain PC139T was compared using NCBI BLAST under default settings (e.g., considering only the high-scoring segment pairs (HSPs) from the best 250 hits) with the most recent release of the Greengenes database [6] and the relative frequencies, of taxa and keywords (reduced to their stem [7]) were determined, weighted by BLAST scores. The most frequently occurring genus was Bacteroides (100.0\%) (20 hits in total). Regarding the single hit to sequences from members of the species, the identity within HSPs was $99.9 \%$, whereas the coverage by HSPs was $98.0 \%$. Regarding the twelve hits to sequences from other members of the genus, the average identity within HSPs was $92.9 \%$, whereas the average coverage by HSPs was $62.1 \%$. Among all other species, the one yielding the highest score was B. propionicifaciens, which corresponded to an identity of $94.6 \%$ and an HSP coverage of $84.5 \%$. The highest-scoring environmental sequence was AF445205 ('Swine fecal isolate str. FPC111'), which showed an identity of $99.8 \%$ and an HSP coverage of $100.0 \%$. The most frequently occurring keywords within the labels of environmental samples which yielded hits were 'human' (6.3\%), 'fecal' (5.5\%), 'effect' (4.4\%), 'antibiot, deep, gut, microbiota, pervas, sequenc' (4.3\%) and 'feedlot' (4.2\%) (230 hits in total). Environmental samples which yielded hits of a higher score than the highest scoring species were not found.

Figure 1 shows the phylogenetic neighborhood of B. coprosuis in a $16 \mathrm{~S}$ rRNA based tree. The sequences of the three $16 \mathrm{~S}$ rRNA gene copies in the genome differ from each other by up to seven nucleotides, and differ by up to six nucleotides from the previously published 16S rRNA sequence (AF319778).

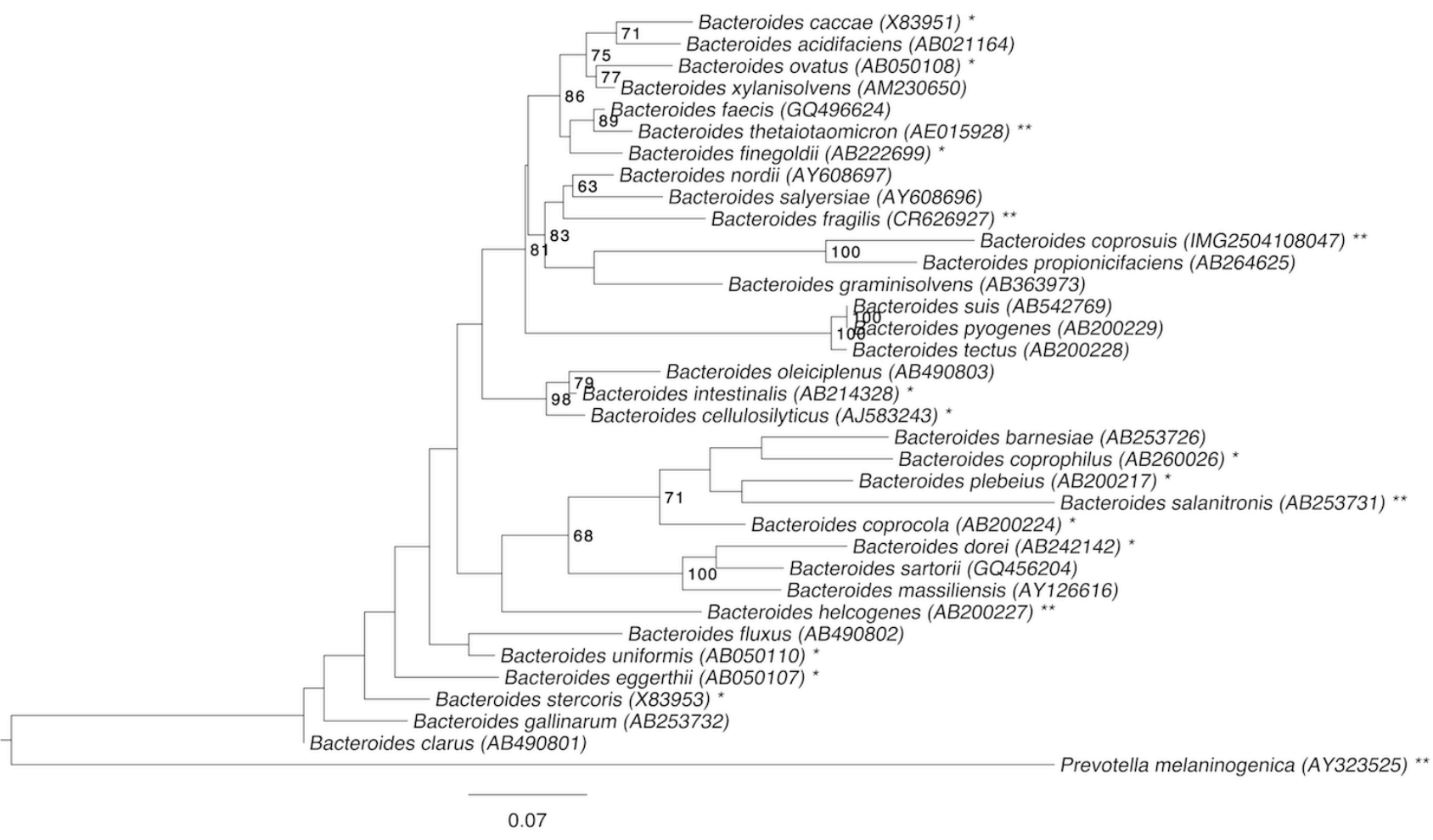

Figure 1. Phylogenetic tree highlighting the position of $B$. coprosuis relative to the other type strains within the genus Bacteroides. The tree was inferred from 1,412 aligned characters [8,9] of the 16S rRNA gene sequence under the maximum likelihood criterion [10] and rooted in accordance with the current taxonomy. The branches are scaled in terms of the expected number of substitutions per site. Numbers to the right of bifurcations are support values from 1,000 bootstrap replicates [11] if larger than $60 \%$. Lineages with type strain genome sequencing projects registered in GOLD [12] and unpublished are marked with one asterisk, those listed as published (as well as the target genome) with two asterisks [13-17], and CP002122/3 for Prevotella melaninogenica. 
The cells of $B$. coprosuis are generally rod-shaped $(0.5-1.5 \times 0.8-3.0 \mu \mathrm{m})$ with tapered ends (Figure 2 ). The cells are usually arranged singly or in pairs [2]. B. coprosuis is a Gram-negative and non sporeforming bacterium (Table 1). The organism is finally described to be non-motile; only four genes associated with motility have been found in the genome (see below). The organism grows at temperatures from 25 to $37^{\circ} \mathrm{C}$, but not at $42^{\circ} \mathrm{C}$ or higher; the optimal temperature is $37^{\circ} \mathrm{C}$ [2]. $\mathrm{B} . \mathrm{Co}$ prosuis is a strictly anaerobic chemoorganotroph and is able to grow on media containing glucose, maltose and chondroitin sulfate, but no growth was observed on arabinogalactan, arabinose, cellobiose, corn-fibre xylan, corn-spelt xylan, fructose or xylose [2]. The organism produces acid from mannose, but not from raffinose. It hydrolyzes esculin and starch, but does not liquify gelatin, reduce nitrate nor produce indole from tryptophan [2]. Growth is possible in the presence of $20 \%$ bile [2]. Major fermentation products from glucose are acetic acid (8.0-15.0 mM), succinic acid (7.5-10.0 $\mathrm{mM}$ ) and propionic acid (4.0-22.0 mM) [2]. B. coprosuis shows activity for alkaline and acid phosphatase, $\alpha$-fucosidase, $\beta$-galactosidases, $\alpha$ - and $\beta$ - glucosidases, $N$-acetyl- $\beta$-glucosaminidase, chymotrypsin, esterase C4, ester lipase C8, lipase C14, cystine arylamidase, leucyl glycine arylamidase, alanine arylamidase, arginine arylamidase and glutamyl glutamic acid arylamidase. No activity was detected for urease, catalase, oxidase, trypsin, arginine dihydrolase, $\beta$-galactosidase 6phosphate, $\beta$-glucuronidase, $\alpha$-arabinosidase, $\alpha$ mannosidase and glutamic acid, glycine, histidine, leucine, phenylalanine, proline, pyroglutamic acid, serine, tyrosine and valine arylamidase [2]. B. coprosuis is resistant to ampicillin $(100 \mu \mathrm{g} / \mathrm{ml})$, cefoxitin $(20 \mu \mathrm{g} / \mathrm{ml})$, erythromycin $(10 \mu \mathrm{g} / \mathrm{ml})$, gentamicin $(200 \mu \mathrm{g} / \mathrm{ml})$ and tetracycline $(3 \mu \mathrm{g} / \mathrm{ml})$.

\section{Chemotaxonomy}

Little chemotaxonomic information is available for strain PC139T. Thus far, only the fatty acid composition has been elucidated. The major fatty acids found were anteiso- $\mathrm{C}_{15: 0}(31 \%)$, iso- $\mathrm{C}_{17: 0} 3-\mathrm{OH}$ (17\%), iso- $\mathrm{C}_{17: 0}(10 \%)$, iso- $\mathrm{C}_{15: 0}(8 \%)$ and $\mathrm{C}_{15: 0}$ (8\%). Fatty acids $\mathrm{C}_{16: 0}(3.5 \%)$, anteiso- $\mathrm{C}_{17: 0}(3 \%)$, $\mathrm{C}_{18: 1} \omega 9 \mathrm{c}(2 \%), \mathrm{C}_{17: 0}(2 \%)$, anteiso- $\mathrm{C}_{17: 1} \omega 9 \mathrm{c}(2 \%)$, $\mathrm{C}_{18: 0}(1 \%)$ and iso- $\mathrm{C}_{13: 0}(1 \%)$ were found in minor amounts [2].

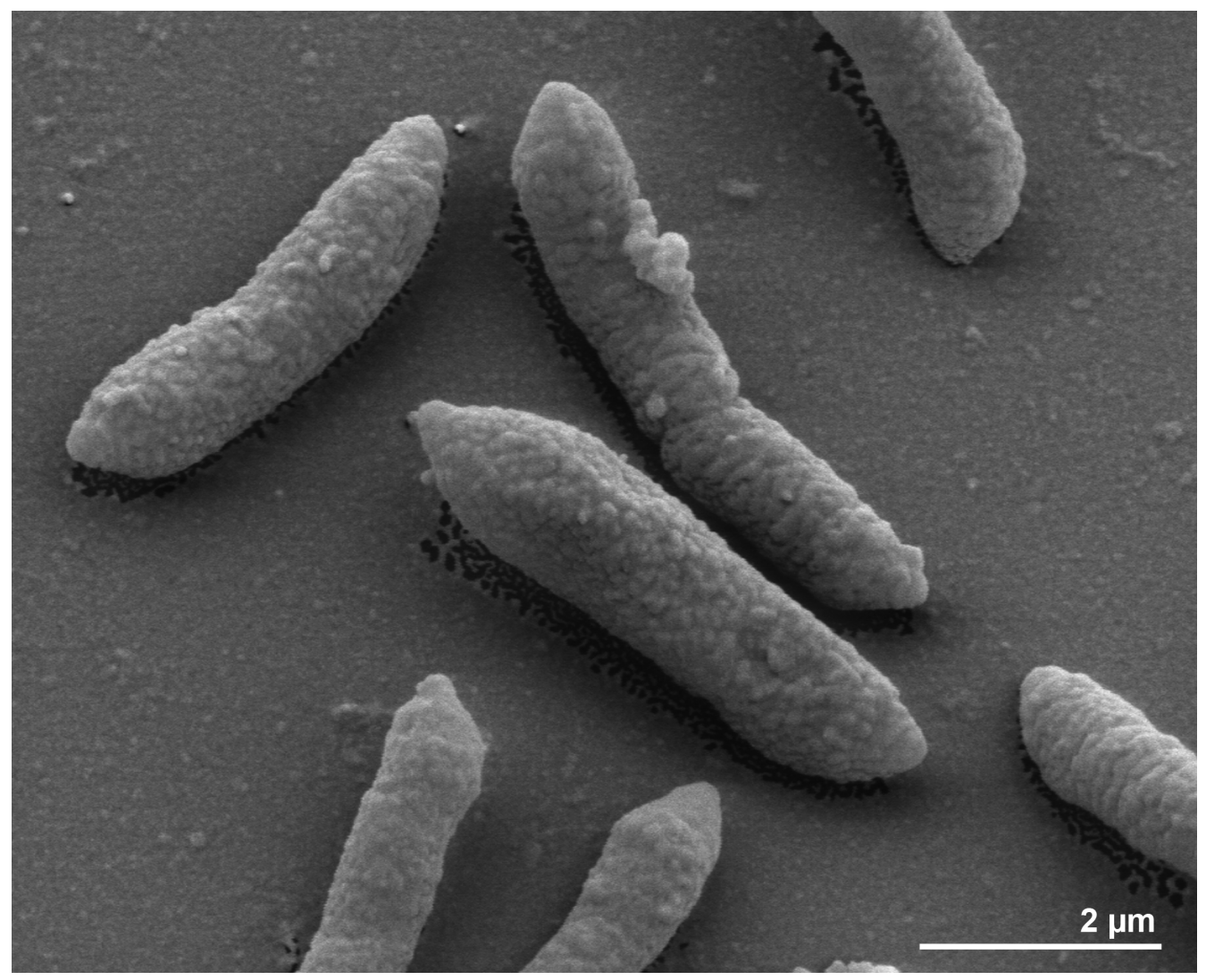

Figure 2. Scanning electron micrograph of $B$. coprosuis $\mathrm{PC} 139^{\top}$ 
Table 1. Classification and general features of $B$. coprosuis $\mathrm{PC} 139^{\top}$ according to the MIGS recommendations [18].

\begin{tabular}{|c|c|c|c|}
\hline MIGS ID & Property & Term & Evidence code \\
\hline & \multirow{8}{*}{ Current classification } & Domain Bacteria & TAS [19] \\
\hline & & Phylum Bacteroidetes & TAS $[20]$ \\
\hline & & Class 'Bacteroidia' & TAS [21] \\
\hline & & Order 'Bacteroidales' & TAS [22] \\
\hline & & Family Bacteroidaceae & TAS $[23,24]$ \\
\hline & & Genus Bacteroides & TAS $[23,25-28]$ \\
\hline & & Species Bacteroides coprosuis & TAS [2] \\
\hline & & Type strain PC139 & TAS [2] \\
\hline & Gram stain & negative & TAS [2] \\
\hline & Cell shape & rod-shaped & TAS [2] \\
\hline & Motility & non-motile & TAS [2] \\
\hline & Sporulation & none & TAS [2] \\
\hline & Temperature range & $25^{\circ} \mathrm{C}-37^{\circ} \mathrm{C}$ & TAS [2] \\
\hline & Optimum temperature & $37^{\circ} \mathrm{C}$ & TAS [2] \\
\hline & Salinity & not reported & \\
\hline \multirow[t]{3}{*}{ MIGS-22 } & Oxygen requirement & strictly anaerobic & TAS [2] \\
\hline & Carbon source & carbohydrates & TAS [2] \\
\hline & Energy metabolism & chemoorganotroph & TAS [2] \\
\hline MIGS-6 & Habitat & most probably Sus scrofa domestica & TAS [2] \\
\hline MIGS-15 & Biotic relationship & free-living & NAS \\
\hline \multirow[t]{3}{*}{ MIGS-14 } & Pathogenicity & none & NAS \\
\hline & Biosafety level & 1 & TAS [29] \\
\hline & Isolation & pig feces, manure storage pit & TAS [2] \\
\hline MIGS-4 & Geographic location & USA & TAS [2] \\
\hline MIGS-5 & Sample collection time & 2005 or before & NAS \\
\hline MIGS-4.1 & Latitude & not reported & \\
\hline MIGS-4.2 & Longitude & not reported & \\
\hline MIGS-4.3 & Depth & not reported & \\
\hline MIGS-4.4 & Altitude & not reported & \\
\hline
\end{tabular}

Evidence codes - IDA: Inferred from Direct Assay (first time in publication); TAS: Traceable Author Statement (i.e., a direct report exists in the literature); NAS: Non-traceable Author Statement (i.e., not directly observed for the living, isolated sample, but based on a generally accepted property for the species, or anecdotal evidence). These evidence codes are from of the Gene Ontology project [30]. If the evidence code is IDA, then the property was directly observed by one of the authors or an expert mentioned in the acknowledgements.

\section{Genome sequencing and annotation Genome project history}

This organism was selected for sequencing on the basis of its phylogenetic position [31], and is part of the Genomic Encyclopedia of Bacteria and Archaea project [32]. The genome project is deposited in the Genomes On Line Database [12] and the complete genome sequence is deposited in GenBank. Sequencing, finishing and annotation were performed by the DOE Joint Genome Institute (JGI). A summary of the project information is shown in Table 2. 
Table 2. Genome sequencing project information

\begin{tabular}{|c|c|c|}
\hline MIGS ID & Property & Term \\
\hline MIGS-31 & Finishing quality & Non-contiguous finished \\
\hline MIGS-28 & Libraries used & $\begin{array}{l}\text { Three genomic libraries: one } 454 \text { pyrosequence standard library, } \\
\text { one } 454 \text { PE library ( } 7 \text { kb insert size), one Illumina library }\end{array}$ \\
\hline MIGS-29 & Sequencing platforms & Illumina GAii, 454 GS FLX Titanium \\
\hline MIGS-31.2 & Sequencing coverage & $283.0 \times$ Illumina; $36.6 \times$ pyrosequence \\
\hline MIGS-30 & Assemblers & $\begin{array}{l}\text { Newbler version } 2.3 \text {-PreRelease-09-14-2009, } \\
\text { Velvet version } 0.7 .63 \text {, phrap version } 4.24\end{array}$ \\
\hline \multirow[t]{6}{*}{ MIGS-32 } & Gene calling method & Prodigal 1.4, GenePRIMP \\
\hline & INSDC ID & AFFW00000000 \\
\hline & Genbank Date of Release & May 12, 2011 \\
\hline & GOLD ID & Gi03975 \\
\hline & NCBI project ID & 40779 \\
\hline & Database: IMG-GEBA & 2503982039 \\
\hline \multirow[t]{2}{*}{ MIGS-13 } & Source material identifier & DSM 18011 \\
\hline & Project relevance & Tree of Life, GEBA \\
\hline
\end{tabular}

\section{Growth conditions and DNA isolation}

B. coprosuis PC139', DSM 18011, was grown anaerobically in DSMZ medium 104 (modified PYGmedium $)+$ rumen fluid $(200 \mu \mathrm{l} / 10 \mathrm{ml})$ [33] at $37^{\circ} \mathrm{C}$. DNA was isolated from $0.5-1 \mathrm{~g}$ of cell paste using MasterPure Gram-positive DNA purification kit (Epicentre MGP04100) following the standard protocol as recommended by the manufacturer with modification st/DL for cell lysis as described in Wu et al. 2009 [32]. DNA is available through the DNA Bank Network [34].

\section{Genome sequencing and assembly}

The genome was sequenced using a combination of Illumina and 454 sequencing platforms. All general aspects of library construction and sequencing can be found at the JGI website [35]. Pyrosequencing reads were assembled using the Newbler assembler version 2.3-PreRelease-09-142009 (Roche). The initial Newbler assembly consisting of 100 contigs in two scaffolds was converted into a phrap assembly [36] by making fake reads from the consensus, to collect the read pairs in the 454 paired end library. Illumina GAii sequencing data (920.8 Mb) was assembled with Velvet, version 0.7.63 [37] and the consensus sequences were shredded into $1.5 \mathrm{~kb}$ overlapped fake reads and assembled together with the 454 data. The 454 draft assembly was based on 109.0 $\mathrm{Mb} 454$ draft data and all of the 454 paired end data. Newbler parameters are -consed -a 50 -l 350 -g -m -ml 20. The Phred/Phrap/Consed software package [36] was used for sequence assembly and quality assessment in the subsequent finishing process. After the shotgun stage, reads were as- sembled with parallel phrap (High Performance Software, LLC). Possible mis-assemblies were corrected with gapResolution [35], Dupfinisher, or sequencing cloned bridging PCR fragments with subcloning or transposon bombing (Epicentre Biotechnologies, Madison, WI) [38]. Gaps between contigs were closed by editing in Consed, by PCR and by Bubble PCR primer walks (J.-F.Chang, unpublished). A total of 193 additional reactions and four shatter libraries were necessary to close gaps and to raise the quality of the finished sequence. Illumina reads were also used to correct potential base errors and increase consensus quality using a software Polisher developed at JGI [39]. The error rate of the completed genome sequence is less than 1 in 100,000. Together, the combination of the Illumina and 454 sequencing platforms provided $319.6 \times$ coverage of the genome. The final assembly contained 252,927 pyrosequence and $24,365,026$ Illumina reads.

\section{Genome annotation}

Genes were identified using Prodigal [40] as part of the Oak Ridge National Laboratory genome annotation pipeline, followed by a round of manual curation using the JGI GenePRIMP pipeline [41]. The predicted CDSs were translated and used to search the National Center for Biotechnology Information (NCBI) non-redundant database, UniProt, TIGR-Fam, Pfam, PRIAM, KEGG, COG, and InterPro databases. Additional gene prediction analysis and functional annotation was performed within the Integrated Microbial Genomes - Expert Review (IMG-ER) platform [42]. 


\section{Genome properties}

The genome consists of a 2,991,798 bp long circular chromosome (in one contig with one remaining unclosed sequencing gap), with a $\mathrm{G}+\mathrm{C}$ content of $35.0 \%$ (Table 3 ). Of the 2,539 genes predicted, 2,461 were protein-coding genes, and 78 RNAs; 68 pseudogenes were also identified. The majority of the protein-coding genes (66.4\%) were assigned with a putative function while the remaining ones were annotated as hypothetical proteins. The distribution of genes into COGs functional categories is presented in Table 4.

\section{Insights from the genome sequence}

Figure 3 shows synteny dot plots of three Bacteroides type strain genomes ( $B$. helcogenes, $B$. salanitronis, $B$. coprosuis) with each other. In all three pairwise comparisons it becomes visible that there does not exist a high collinearity between these species of the genus Bacteroides.

The Genome-to-Genome Distance Calculator, GGDC $[43,44]$ was used for the estimation of the overall similarity between the three Bacteroides genomes. The system calculates the distances by comparing the genomes to obtain HSPs (highscoring segment pairs) and interfering distances from the set of formulas (1 HSP length / total length; 2 identities / HSP length; 3 identities / total length). The comparison of $B$. coprosuis with $B$. helcogenes and $B$. salanitronis revealed that only $6.1 \%$ and $3.3 \%$, respectively, of the average of the genome lengths are covered with HSPs. The identity within the HSPs was $82.3 \%$ and $82.1 \%$, respectively, whereas the identity over the whole genome was $5.0 \%$ and $2.7 \%$, respectively. The comparison of $B$. salanitronis with $B$. helcogenes revealed that $11.4 \%$ of the genome is covered with HSPs, with an identity within in the HSPs of $81.4 \%$ and an identity over the whole genome of $9.2 \%$. According to these calculations the similarity between $B$. salanitronis and $B$. helcogenes is higher than the similarity between $B$. coprosuis and $B$. salanitronis as well as the similarity between B. coprosuis and B. helcogenes.

Table 3. Genome Statistics

\begin{tabular}{lrr}
\hline Attribute & Value & \% of Total \\
\hline Genome size (bp) & $2,991,798$ & $100.00 \%$ \\
DNA coding region (bp) & $2,551,700$ & $85.29 \%$ \\
DNA G+C content (bp) & $1,046,824$ & $34.99 \%$ \\
Number of replicons & 1 & \\
Extrachromosomal elements & 0 & \\
Total genes & 2,539 & $100.00 \%$ \\
RNA genes & 78 & $3.07 \%$ \\
rRNA operons & 3 & \\
Protein-coding genes & 2,461 & $96.93 \%$ \\
Pseudo genes & 68 & $2.68 \%$ \\
Genes with function prediction & 1,686 & $66.40 \%$ \\
Genes in paralog clusters & 272 & $10.71 \%$ \\
Genes assigned to COGs & 1,631 & $64.24 \%$ \\
Genes assigned Pfam domains & 1,795 & $70.70 \%$ \\
Genes with signal peptides & 669 & $26.35 \%$ \\
Genes with transmembrane helices & 580 & $22.84 \%$ \\
CRISPR repeats & 1 & \\
\hline
\end{tabular}


Table 4. Number of genes associated with the general COG functional categories

\begin{tabular}{|c|c|c|c|}
\hline Code & value & \%age & Description \\
\hline J & 143 & 8.1 & Translation, ribosomal structure and biogenesis \\
\hline A & 0 & 0.0 & RNA processing and modification \\
\hline K & 84 & 4.8 & Transcription \\
\hline $\mathrm{L}$ & 140 & 8.0 & Replication, recombination and repair \\
\hline B & 0 & 0.0 & Chromatin structure and dynamics \\
\hline $\mathrm{D}$ & 18 & 1.0 & Cell cycle control, cell division, chromosome partitioning \\
\hline $\mathrm{Y}$ & 0 & 0.0 & Nuclear structure \\
\hline V & 34 & 1.9 & Defense mechanisms \\
\hline $\mathrm{T}$ & 59 & 3.4 & Signal transduction mechanisms \\
\hline M & 154 & 8.8 & Cell wall/membrane/envelope biogenesis \\
\hline $\mathrm{N}$ & 4 & 0.2 & Cell motility \\
\hline Z & 0 & 0.0 & Cytoskeleton \\
\hline W & 0 & 0.0 & Extracellular structures \\
\hline$U$ & 41 & 2.3 & Intracellular trafficking, secretion, and vesicular transport \\
\hline $\mathrm{O}$ & 55 & 3.1 & Posttranslational modification, protein turnover, chaperones \\
\hline $\mathrm{C}$ & 113 & 6.4 & Energy production and conversion \\
\hline G & 119 & 6.8 & Carbohydrate transport and metabolism \\
\hline $\mathrm{E}$ & 140 & 8.0 & Amino acid transport and metabolism \\
\hline $\mathrm{F}$ & 64 & 3.7 & Nucleotide transport and metabolism \\
\hline $\mathrm{H}$ & 111 & 6.3 & Coenzyme transport and metabolism \\
\hline I & 44 & 2.5 & Lipid transport and metabolism \\
\hline$P$ & 118 & 6.7 & Inorganic ion transport and metabolism \\
\hline Q & 14 & 0.8 & Secondary metabolites biosynthesis, transport and catabolism \\
\hline $\mathrm{R}$ & 197 & 11.2 & General function prediction only \\
\hline S & 102 & 5.8 & Function unknown \\
\hline - & 908 & 35.7 & Not in COGs \\
\hline
\end{tabular}


A

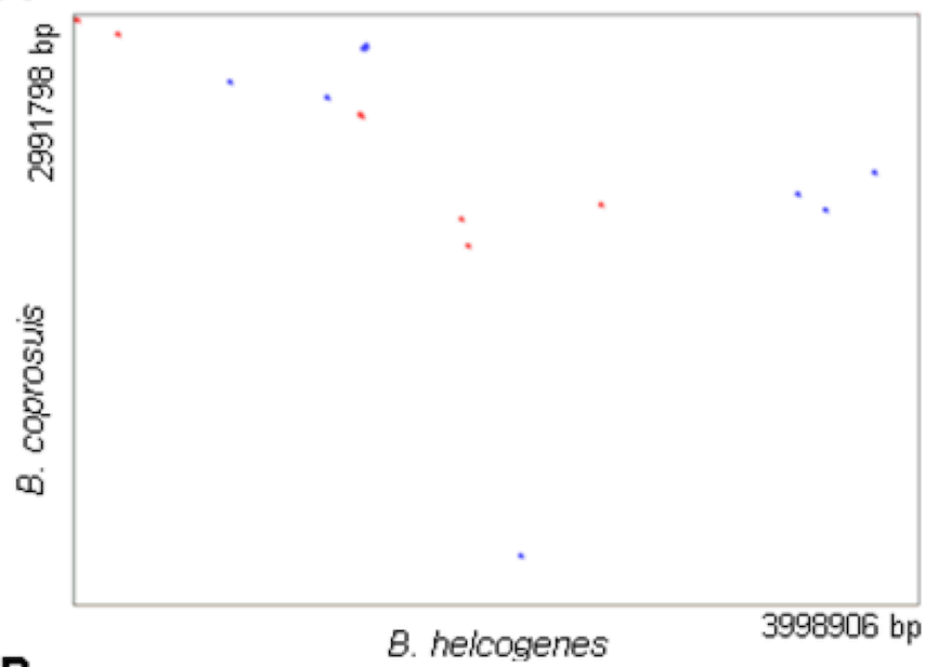

B
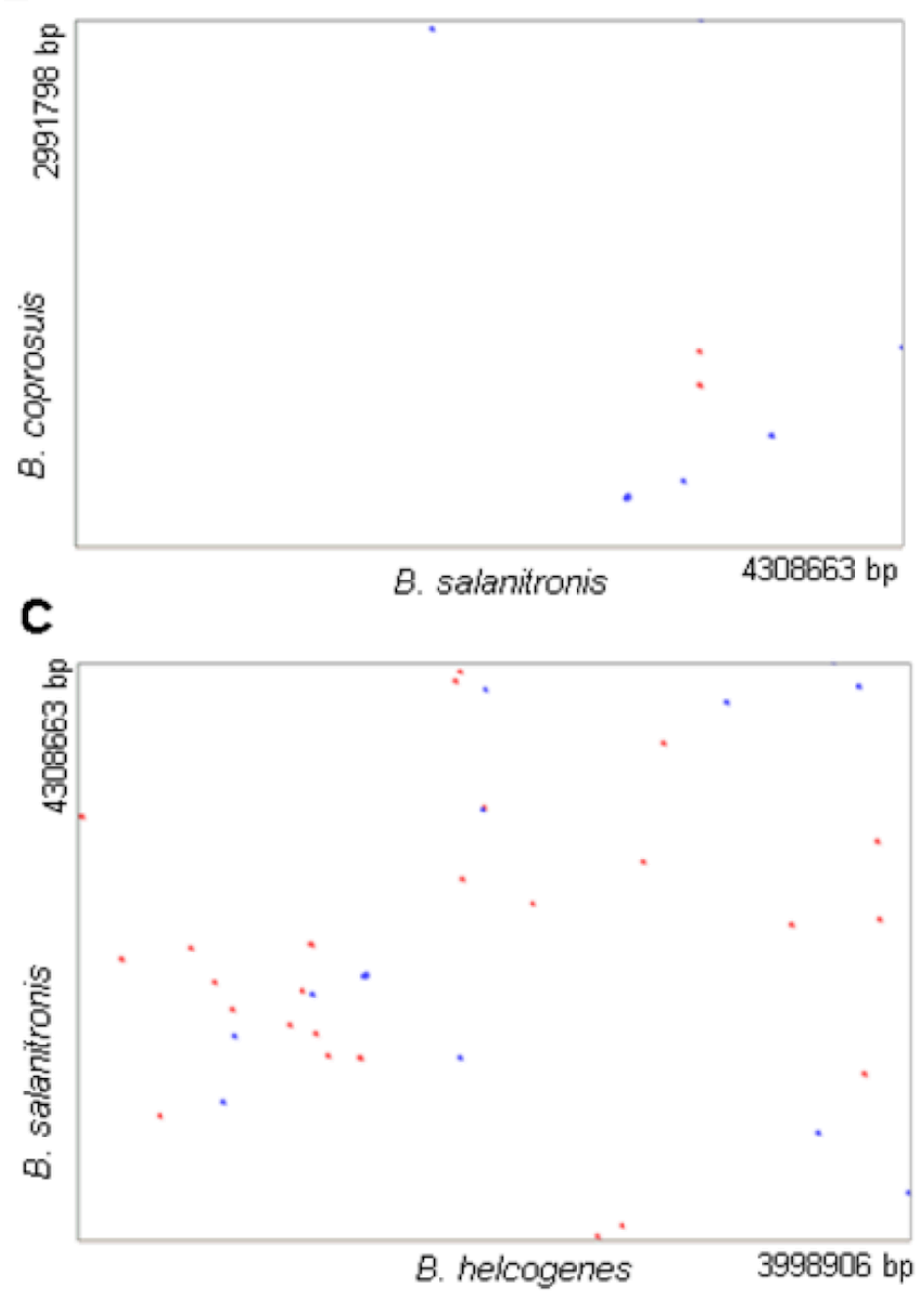

Figure 3. Synteny dot plots based on the genome sequences of A: B. coprosuis and B. helcogenes; B: B. coprosuis and B. salanitronis; $C$ : $B$. salanitronis and B. helcogenes. Blue dots represent regions of similarity found on parallel strands and red dots show regions of similarity found on antiparallel strands. 


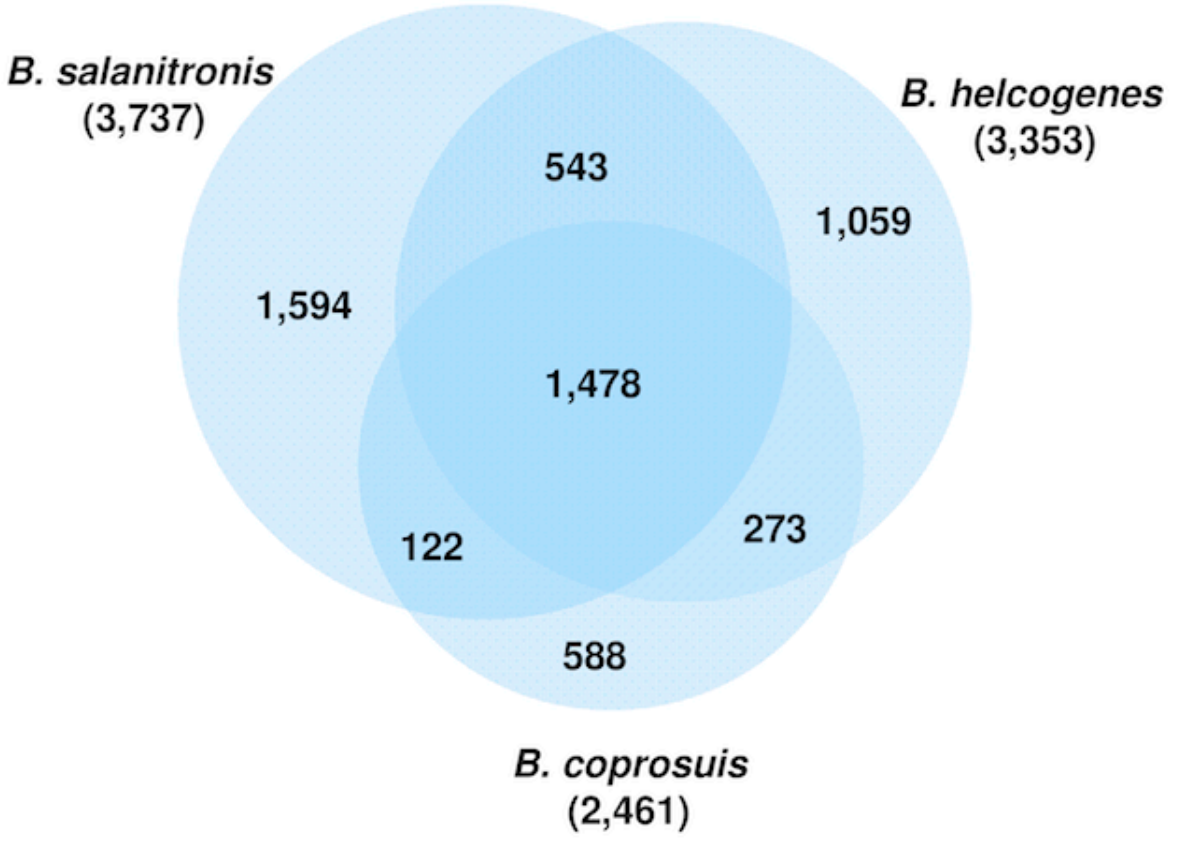

Figure 4. Venn diagram depicting the intersections of proteins sets (total numbers in parentheses) of the three sequenced Bacteroides genomes.

The genome size of $B$. coprosuis (3 Mb) is significantly smaller than those of $B$. helcogenes $(4 \mathrm{Mb})$ and $B$. salanitronis $(4.3 \mathrm{Mb})$ and the $\mathrm{G}+\mathrm{C}$-content of the $B$. coprosuis genome $(35 \%)$ is much lower than the $\mathrm{G}+\mathrm{C}$-content of $B$. helcogenes $(45 \%)$ and $B$. salanitronis $(46 \%)$ genomes. The Venn diagram (Figure 4 ) shows the number of shared genes. $B$. salanitronis and $B$. helcogenes share a great number of genes (543 genes) that are not present in $B$. coprosuis. This fraction of genes includes genes coding for glycoside hydrolases, which are responsible for the degradation of polysaccharides. Only 12 glycoside hydrolases were identified in the

\section{Acknowledgements}

We would like to gratefully acknowledge the help of Sabine Welnitz (DSMZ) for growing B. coprosuis cultures. This work was performed under the auspices of the US Department of Energy Office of Science, Biological and Environmental Research Program, and by the University of California, Lawrence Berkeley National Laboratory under contract No. DE-AC02-05CH11231,

\section{References}

1. Garrity G. NamesforLife. BrowserTool takes expertise out of the database and puts it right in the browser. Microbiol Today 2010; 7:1. genome of $B$. coprosuis, whereas the number of glycoside hydrolases identified in $B$. helcogenes and $B$. salanitronis, is much higher, 38 and 45 , respectively. Whereas only two transposase genes were identified in the genome of $B$. helcogenes, the genomes of $B$. coprosuis and $B$. salanitronis encode a high number of transposases, 34 and 29, respectively. As a consequence, genome rearrangements can occur, which result in a quite dynamic genome structure (Figure 4). Only a small number of the genes (588 genes) found in $B$. coprosuis are not present in B. helcogenes and/or B. salanitronis.

Lawrence Livermore National Laboratory under Contract No. DE-AC52-07NA27344, and Los Alamos National Laboratory under contract No. DE-AC0206NA25396, UT-Battelle and Oak Ridge National Laboratory under contract DE-AC05-000R22725, as well as German Research Foundation (DFG) INST 599/1-2.

2. Whitehead TR, Cotta MA, Collins MD, Falsen E, Lawson PA. Bacteroides coprosuis sp. nov., isolated from swine-manure storage pits. Int / Syst 
Evol Microbiol 2005; 55:2515-2518. PubMed doi:10.1099/ijs.0.63869-0

3. Comstock LE. Importance of glycans to the hostbacteroides mutualism in the mammalian intestine. Cell Host Microbe 2009; 5:522-526. PubMed doi:10.1016/j.chom.2009.05.010

4. Bäckhed F, Ley RE, Sonnenburg JL, Peterson DA, Gordon JI. Host-bacterial mutualism in the human intestine. Science 2005; 307:1915-1920. PubMed doi:10.1126/science. 1104816

5. Hentges DJ. Role of the intestinal flora in host defense against infection. In Human Intestinal Microflora in Health and Disease 1983; pp.311-331. Edited by D. J. Hentges. New York: Academic Press.

6. DeSantis TZ, Hugenholtz P, Larsen N, Rojas M, Brodie EL, Keller K, Huber T, Dalevi D, Hu P, Andersen GL. Greengenes, a chimera-checked 16S rRNA gene database and workbench compatible with ARB. Appl Environ Microbiol 2006; 72:5069-5072. PubMed doi:10.1128/AEM.03006-05

7. Porter MF. An algorithm for suffix stripping. Program: electronic library and information systems 1980; 14:130-137.

8. Castresana J. Selection of conserved blocks from multiple alignments for their use in phylogenetic analysis. Mol Biol Evol 2000; 17:540-552. PubMed

9. Lee C, Grasso C, Sharlow MF. Multiple sequence alignment using partial order graphs. Bioinformatics 2002; 18:452-464. PubMed doi:10.1093/bioinformatics/18.3.452

10. Stamatakis A, Hoover $\mathrm{P}$, Rougemont J. A rapid bootstrap algorithm for the RAxML Web servers. Syst Biol 2008; 57:758-771. PubMed doi:10.1080/10635150802429642

11. Pattengale ND, Alipour M, Bininda-Emonds ORP, Moret BME, Stamatakis A. How many bootstrap replicates are necessary? Lect Notes Comput Sci 2009; 5541:184-200. doi:10.1007/978-3-64202008-7 13

12. Liolios K, Chen IM, Mavromatis K, Tavernarakis N, Hugenholtz P, Markowitz VM, Kyrpides NC. The Genomes On Line Database (GOLD) in 2009: status of genomic and metagenomic projects and their associated metadata. Nucleic Acids Res 2010; 38:D346-D354. PubMed doi:10.1093/nar/gkp848

13. Cerdeño-Tárraga AM, Patrick $S$, Crossman LC, Blakely G, Abratt V, Lennard N, Poxton I, Duer- den B, Harris B, Quail MA, et al. Extensive DNA inversions in the $B$. fragilis genome control variable gene expression. Science 2005; 307:14631465. PubMed doi:10.1126/science.1107008

14. Pati A, Gronow S, Zeytun A, Lapidus A, Nolan M, Hammon N, Deshpande S, Cheng JF, Tapia R, Han $C$, et al. Complete genome sequence of Bacteroides helcogenes type strain (P36-108T). Stand Genomic Sci 2011; 4:45-53. PubMed doi:10.4056/sigs.1513795

15. Xu J, Bjursell MK, Himrod J, Deng S, Carmichael LK, Chiang HC, Hooper LV, Gordon JI. A genomic view of the human-Bacteroides thetaiotaomicron symbiosis. Science 2003; 299:2074-2076. PubMed doi:10.1126/science.1080029

16. Xu J, Mahowald MA, Ley RE, Lozupone CA, Hamady M, Martens EC, Henrissat B, Coutinho PM, Minx $P$, Latreille $P$, et al. Evolution of symbiotic bacteria in the distal human intestine. PLOS Biol 2007; 5:e156. PubMed doi:10.1371/journal.pbio.0050156

17. Gronow S, Held B, Lucas S, Lapidus A, Glavina Del Rio T, Nolan M, Tice H, Deshpande S, Cheng JF, Pitluck S, et al. Complete genome sequence of Bacteroides salanitronis type strain $\left(B L 78^{\top}\right)$. Stand Genomic Sci 2011; 4:191-199.

18. Field D, Garrity G, Gray T, Morrison N, Selengut J, Sterk P, Tatusova T, Thomson N, Allen MJ, Angiuoli $S V$, et al. The minimum information about a genome sequence (MIGS) specification. Nat Biotechnol 2008; 26:541-547. PubMed doi:10.1038/nbt1360

19. Woese CR, Kandler O, Wheelis ML. Towards a natural system of organisms: proposal for the domains Archaea, Bacteria, and Eucarya. Proc Natl Acad Sci USA 1990; 87:4576-4579. PubMed doi:10.1073/pnas.87.12.4576

20. Garrity GM, Holt JG. The Road Map to the Manual. In: Garrity GM, Boone DR, Castenholz RW (eds), Bergey's Manual of Systematic Bacteriology, Second Edition, Volume 1, Springer, New York, 2001, p. 119-169.

21. Ludwig W, Euzeby J, Whitman WG. Draft taxonomic outline of the Bacteroidetes, Planctomycetes, Chlamydiae, Spirochaetes, Fibrobacteres, Fusobacteria, Acidobacteria, Verrucomicrobia, Dictyoglomi, and Gemmatimonadetes. http://www.bergeys.org/outlines/Bergeys_Vol_4 Outline.pdf. Taxonomic Outline 2008.

22. Garrity GM, Holt JG. 2001. Taxonomic outline of the Archaea and Bacteria, p. 155-166. In: Garrity GM, Boone DR, Castenholz RW (eds), Bergey's 
Manual of Systematic Bacteriology, 2nd ed, vol. 1. Springer, New York.

23. Skerman VBD, McGowan V, Sneath PHA. Approved Lists of Bacterial Names. Int / Syst Bacteriol 1980; 30:225-420. doi:10.1099/0020771330-1-225

24. Pribram E. Klassification der Schizomyceten. Klassifikation der Schizomyceten (Bakterien), Franz Deuticke, Leipzig, 1933, p. 1-143.

25. Castellani A, Chalmers AJ. Genus Bacteroides Castellani and Chalmers, 1918. Manual of Tropical Medicine, Third Edition, Williams, Wood and Co., New York, 1919, p. 959-960.

26. Holdeman LV, Moore WEC. Genus I. Bacteroides Castellani and Chalmers 1919, 959. In: Buchanan RE, Gibbons NE (eds), Bergey's Manual of Determinative Bacteriology, Eighth Edition, The Williams and Wilkins Co., Baltimore, 1974, p. 385404.

27. Cato EP, Kelley RW, Moore WEC, Holdeman LV. Bacteroides zoogleoformans, Weinberg, Nativelle, and Prévot 1937) corrig. comb. nov.: emended description. Int J Syst Bacteriol 1982; 32:271-274. doi:10.1099/00207713-32-3-271

28. Shah HN, Collins MD. Proposal to restrict the genus Bacteroides (Castellani and Chalmers) to Bacteroides fragilis and closely related species. Int J Syst Bacteriol 1989; 39:85-87. doi:10.1099/00207713-39-1-85

29. BAuA. Classification of bacteria and archaea in risk groups. TRBA 2005; 466:84.

30. Ashburner M, Ball CA, Blake JA, Botstein D, Butler $\mathrm{H}$, Cherry JM, Davis AP, Dolinski K, Dwight SS, Eppig JT, et al. Gene Ontology: tool for the unification of biology. Nat Genet 2000; 25:25-29. PubMed doi:10.1038/75556

31. Klenk HP, Göker M. En route to a genome-based classification of Archaea and Bacteria? Syst Appl Microbiol 2010; 33:175-182. PubMed doi:10.1016/j.syapm.2010.03.003

32. Wu D, Hugenholtz P, Mavromatis K, Pukall R, Dalin E, Ivanova NN, Kunin V, Goodwin L, Wu $M$, Tindall BJ, et al. A phylogeny-driven genomic encyclopaedia of Bacteria and Archaea. Nature 2009; 462:1056-1060. $\underline{\text { PubMed }}$ doi:10.1038/nature08656

33. List of growth media used at DSMZ: http//www.dsmz.de/microorganisms/media_list.p $\underline{\mathrm{hp}}$
34. Gemeinholzer B, Dröge G, Zetzsche H, Haszprunar G, Klenk HP, Güntsch A, Berendsohn WG, Wägele JW. The DNA Bank Network: the start from a German initiative. Biopreservation and Biobanking 2011; 9:51-55. doi:10.1089/bio.2010.0029

35. The DOE Joint Genome Institute. http://www.jgi.doe.gov

36. Phrap and Phred for Windows. MacOS, Linux, and Unix. http://www.phrap.com

37. Zerbino DR, Birney E. Velvet: algorithms for de novo short read assembly using de Bruijn graphs. Genome Res 2008; 18:821-829. PubMed doi:10.1101/gr.074492.107

38. Sims D, Brettin T, Detter JC, Han C, Lapidus A, Copeland A, Glavina Del Rio T, Nolan M, Chen $\mathrm{F}$, Lucas $\mathrm{S}$, et al. Complete genome sequence of Kytococcus sedentarius type strain $\left(541^{\top}\right)$. Stand Genomic Sci 2009; 1:12-20. PubMed doi:10.4056/sigs.761

39. Lapidus A, LaButti K, Foster B, Lowry S, Trong S, Goltsman E. POLISHER: An effective tool for using ultra short reads in microbial genome assembly and finishing. AGBT, Marco Island, FL, 2008.

40. Hyatt D, Chen GL, LoCascio PF, Land ML, Larimer FW, Hauser LJ. Prodigal: prokaryotic gene recognition and translation initiation site identification. BMC Bioinformatics 2010; 11:119. $\underline{\text { PubMed doi:10.1186/1471-2105-11-119 }}$

41. Pati A, Ivanova NN, Mikhailova N, Ovchinnikova G, Hooper SD, Lykidis A, Kyrpides NC. GenePRIMP: a gene prediction improvement pipeline for prokaryotic genomes. Nat Methods 2010; 7:455-457. PubMed doi:10.1038/nmeth.1457

42. Markowitz VM, Ivanova NN, Chen IMA, Chu K, Kyrpides NC. IMG ER: a system for microbial genome annotation expert review and curation. Bioinformatics 2009; 25:2271-2278. PubMed doi:10.1093/bioinformatics/btp393

43. Auch AF, von Jan M, Klenk HP, Göker M. Digital DNA-DNA hybridization for microbial species delineation by means of genome-to-genome sequence comparison. Stand Genomic Sci 2010; 2:117-134. PubMed doi:10.4056/sigs.531120

44. Auch AF, Klenk HP, Göker M. Standard operational procedure for calculation genome-togenome distances based on high-scoring sequence pairs. Stand Genomic Sci 2010; 2:142148. PubMed doi:10.4056/sigs.541628 